\title{
Regionalisation for lake level simulation - the case of Lake Tana in the Upper Blue Nile, Ethiopia
}

\author{
T. H. M. Rientjes ${ }^{1}$, B. U. J. Perera ${ }^{2}$, A. T. Haile ${ }^{1}$, P. Reggiani ${ }^{3}$, and L. P. Muthuwatta ${ }^{4}$ \\ ${ }^{1}$ Department of Water Resources, Faculty of Geoinformation Science and Earth Observation (ITC), Twente University, \\ P.O. Box 6, 7500 AA Enschede, The Netherlands \\ ${ }^{2}$ National Water Supply and Drainage Board, Colombo, Sri Lanka \\ ${ }^{3}$ DELTARES, P.O. Box 177, 2600 MH Delft, The Netherlands \\ ${ }^{4}$ International Water Management Institute, P.O. Box 2075, Colombo, Sri Lanka
}

Received: 14 August 2010 - Published in Hydrol. Earth Syst. Sci. Discuss.: 27 September 2010

Revised: 18 March 2011 - Accepted: 21 March 2011 - Published: 8 April 2011

\begin{abstract}
In this study lake levels of Lake Tana are simulated at daily time step by solving the water balance for all inflow and outflow processes. Since nearly $62 \%$ of the Lake Tana basin area is ungauged a regionalisation procedure is applied to estimate lake inflows from ungauged catchments. The procedure combines automated multi-objective calibration of a simple conceptual model and multiple regression analyses to establish relations between model parameters and catchment characteristics.

A relatively small number of studies are presented on Lake Tana's water balance. In most studies the water balance is solved at monthly time step and the water balance is simply closed by runoff contributions from ungauged catchments. Studies partly relied on simple $a d-h o c$ procedures of area comparison to estimate runoff from ungauged catchments. In this study a regional model is developed that relies on principles of similarity of catchments characteristics. For runoff modelling the HBV-96 model is selected while multiobjective model calibration is by a Monte Carlo procedure. We aim to assess the closure term of Lake Tana's water balance, to assess model parameter uncertainty and to evaluate effectiveness of a multi-objective model calibration approach to make hydrological modeling results more plausible.
\end{abstract}

For the gauged catchments, model performance is assessed by the Nash-Sutcliffe coefficient and Relative Volumetric Error and resulted in satisfactory to good performance for six, large catchments. The regional model is validated and indicated satisfactory to good performance in most

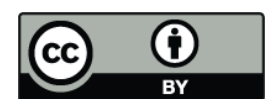

Correspondence to: T. H. M. Rientjes (t.h.m.rientjes@utwente.nl) cases. Results show that runoff from ungauged catchments is as large as $527 \mathrm{~mm}$ per year for the simulation period and amounts to approximately $30 \%$ of Lake Tana stream inflow. Results of daily lake level simulation over the simulation period 1994-2003 show a water balance closure term of $85 \mathrm{~mm}$ per year that accounts to $2.7 \%$ of the total lake inflow. Lake level simulations are assessed by Nash Sutcliffe $(0.91)$ and Relative Volume Error $(2.71 \%)$ performance measures.

\section{Introduction}

During the past decades few studies report on the water balance of Lake Tana. For early work reference is made to (Conway, 1997) who studied the hydrology of the Blue Nile at large. For more recent work reference is made to Chebud and Melesse (2009) and Kebede et al. (2006). In these studies water balance assessments are on monthly time steps. For assessments on daily time step 1 reference is made to Setegn et al. (2008); SMEC (2008) and Wale et al. (2009) who specifically focussed on the water balance of Lake Tana and the hydrology of Lake Tana basin. Stream flow in the basin is not recorded in all catchments that drain to the lake. A review of the above studies shows that the estimates of inflows differ significantly by the selected procedures. According to (Setegn et al., 2008) $45 \%$ of the annual lake water budget is from Gilgel, Gumera, Ribb and Megech rivers that are the four major catchments. Chebud and Melesse (2009) and Kebede et al. (2006) state that these catchments contribute $93 \%$ of the inflow and only $7 \%$ of the lake inflow is from ungauged catchments. SMEC (2008) indicates that $29 \%$ of the lake inflow is from ungauged catchments while Wale et

Published by Copernicus Publications on behalf of the European Geosciences Union. 
al. (2009) indicate that $42 \%$ of the lake inflow is from ungauged systems. It is noted that closure of the lake water balance in most studies (e.g. Kebede et al., 2006; SMEC, 2008) was by stream inflows from ungauged catchments. An actual closure term, however, could not be estimated and any error in one of the balance terms was compensated for by the estimate of the ungauged inflows. For estimation of the closure error of Lake Tana's water balance, only in the work of (Wale et al., 2009) observed lake levels are compared to simulated lake levels by considering a detailed bathymetric survey.

Estimation of stream flow in ungauged basins commonly is based on principles of regionalisation which is the process of transferring information from gauged catchments to ungauged catchment (see Blöschl and Sivapalan, 1995). Merz and Blöschl (2004) describe that regionalisation approaches may be based on similarity of spatial proximity or on similarity of catchment characteristics. The rationale of the first approach is that catchments of close proximity have a similar flow regime and therefore model parameters (MPs) are directly transferable. The rational for the second approach is that optimised MPs are transferable to other catchments in case the physical catchment characteristics (PCCs) are comparable. Transferability is based on the idea that PCCs and (optimised) MPs values are related since, in their functioning, parameters reflect on catchment characteristics. Therefore when establishing a relation between MPs and PCCs the information that is carried by the relation can be used to estimate parameter values from ungauged catchments when catchment characteristics from the ungauged systems are known. Regionalisation may serve to simply estimate stream flow from ungauged catchments but also serves to improve the predictive capability of the selected rainfall-runoff model by assessing model uncertainty. The need to improve the modeling of ungauged catchments is recognized by the International Association of Hydrologic Sciences (IAHS) by adopting the topic as one of the core components for their 10yr Prediction in Ungauged Basins (PUB) project (see Sivapalan et al., 2003).

In Kebebe et al. (2006) and SMEC (2008) regionalisation procedures applied are based on similarity of spatial proximity principles and on simple comparisons of catchment sizes in the Lake Tana basin area. We note that in (Wale et al., 2009) both regionalisation procedures are applied but the similarity of catchment characteristics approach yielded best results where closure of Lake Tana balance was as accurate as $5.0 \%$ of the annual stream flow. This result must be considered the most accurate when compared to results by Kebebe et al. (2006); SMEC (2008) and the other above mentioned studies since the actual closure error of the water balance in those studies is not estimated by assessing how accurate observed lake levels are simulated. Therefore in those studies it remains unclear how well the lake water balance is represented.

The main objective of this study is to assess the closure term of Lake Tana's water balance. Other objectives are to assess model parameter uncertainty and to evaluate effectiveness of an automated multi-objective model calibration approach to make hydrological modeling results more plausible. For model calibration we selected a Monte Carlo simulation procedure while performance assessments are based on the Nash Sutcliffe and Relative Volumetric Error objective functions. Validation of the procedure is by a split sample test. While the automated calibration procedure in this study is fundamentally different from the manual calibration procedure in Wale et al. (2009), different PCCs are tested and the representation lake evaporation has changed since estimation is now based on a more comprehensive satellite based procedure.

This paper is organised as follows. Descriptions of the study area and the availability data are given in Sects. 2 and 3 respectively. In Sect. 4 the hydrological model is presented. Section 5 describes the methodology that covers the calibration of the rainfall-runoff model, the configuration of the regional model and the simulation of water levels of Lake Tana. Section 6 presents and discusses the results of multiobjective model calibration, regionalisation and lake level simulation. In Sect. 7 conclusions are drawn.

\section{Study area}

Lake Tana (1786 m a.s.1.) is the source of the Blue Nile River and has a total drainage area of approximately $15000 \mathrm{~km}^{2}$, of which the lake covers around $3000 \mathrm{~km}^{2}$. The lake is located in the north-western highlands of Ethiopia at $12^{\circ} 00^{\prime} \mathrm{N}$ and $37^{\circ} 15^{\prime} \mathrm{E}$ and receives runoff from more than 40 rivers. Major rivers feeding the lake are Gilgel Abay from the south, Ribb and Gumara from the east and Megech River from the north. From the western side of the lake only small river systems drain to the lake (Fig. 1).

A Digital Elevation Model (DEM) of $90 \mathrm{~m}$ resolution from Shuttle Radar Topography Mission (SRTM-version 4) (http: //srtm.csi.cgiar.org/) has been used to delineate the gauged and ungauged catchments. The hydro-processing tool in ILWIS software (http://52north.org/) has been used for this purpose and eighteen catchments were extracted. Stream flow records for nine catchments are made available by the Ministry of Water Resources (MoWR) in Ethiopia and thus nine catchments are ungauged. Results from catchment delineation, show that among the nine catchments seven catchments are partially gauged while catchments in the northwestern part of the basin are ungauged. We presume that the delineation does not differ much from catchment delineation results in the recent studies mentioned above since the same SRTM Model of $90 \mathrm{~m}$. resolution is used and since similar catchment delineation approaches are applied. Nine catchments are selected for regionalisation based on the availability of runoff data from 1994 to 2003 . The distribution of gauged and ungauged catchments is indicated in Fig. 1. 

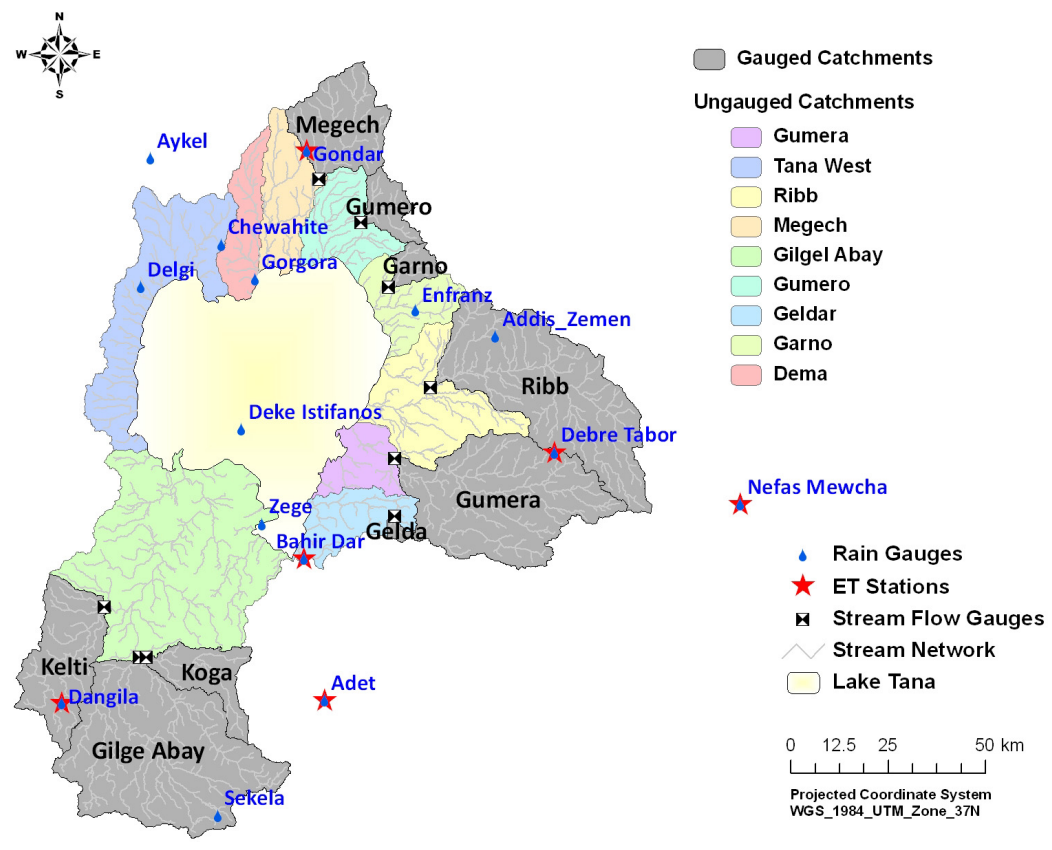

Fig. 1. Gauged and ungauged catchments in the Lake Tana basin. Weather and gauge stations are indicated.

By its large size, Lake Tana has a large storage capacity that only responds slowly to the various processes of the climatic and hydrological cycles. Annual lake level fluctuations are approximately $1.6 \mathrm{~m}$ where lake level fluctuations primarily respond to seasonal influences by the rainy and the dry season. Lake levels reach maxima around September and minima around June with historic maximum and minimum water levels of $1788.02 \mathrm{~m}$ (21 September 1998) and $1784.46 \mathrm{~m}$ (30 June 2003). The only river that drains Lake Tana is the Blue Nile River (Abay River) with a natural outflow that ranges from a minimum of $1075 \mathrm{~mm}^{3}$ (1984) to a maximum of $6181 \mathrm{~mm}^{3}$ (1964). For the period 1976-2006 the average outflow is estimated to be $3732 \mathrm{~mm}^{3}$. For the selected simulation period, observations indicate that outflow of the lake was affected by operation of the Chara Chara weir from the end of 2001 onwards. Visual inspection of stream flow time series indicate that during the construction of the wear (1996-2001) Lake Tana outflow was not affected.

\section{Data availability}

From the National Meteorological Agency (NMA) in Ethiopia time series of daily rainfall from seventeen stations in and close to the study area were collected for the period of 1994-2003. Also from NMA, meteorological data was collected from seven weather stations for estimation of potential evapotranspiration. Data types are daily maximum and minimum temperature, wind speed, relative humidity and sunshine hours. From the database of the Hydrology Department of MoWR daily water levels of Lake Tana and
Abay river gauging station near Bahir Dar were obtained. Daily outflow discharges from Lake Tana were obtained by a stage-discharge rating curve that also was made available by the MoWR. We note that the curve was updated by Wale et al. (2009) and is used in this study as well. Further, stream flow data from seventeen stations was collected from the MoWR in Ethiopia but only nine stations had continuous records covering the period 1994-2003. Runoff time series data were analysed and screened and analysis indicated that records from the smaller (sub)catchments (Gumero, Garno and Gelda) were unreliable while also outliers and errors were observed for the larger catchments. Consistency of the daily time series was analysed by use of double mass curve analysis and by plotting the ratio of incremental differences of rainfall and stream flow. Outliers serve to identify and to correct for erroneous runoff or rainfall data. We note that after screening and identifying catchments with unreliable time series about $38.3 \%$ of the Lake Tana basin area is considered gauged. Catchments selected for regionalisation are Ribb, Gilgel Abay, Gumara, Megech, Koga, Kelti. Satellite data was collected for the Moderate Resolution Imaging Spectro radiometer onboard the TERRA satellite (MODISTERRA) and from the Landsat ETM+ satellite. For the period 2000-2002, the MODIS-TERRA Images were collected from the LAADS Web site (http://ladsweb.nascom.nasa.gov/ data/search.html) for estimation of lake evaporation. The land cover map was prepared by use of the Landsat ETM+ satellite and evaluated based on field data (see Rientjes et al., 2010). A soil map of the major soil groups in the basin was collected from the GIS department of MoWR. 
Soil classification resulted in 6 dominant soil classes. With regard to water storage capacity of Lake Tana, bathymetric relations between area-volume and elevation-volume were available through a bathymetric survey by the Faculty of Geoinformation Science and Earth observation, University of Twente, in 2005. The bathymetric relations were improved by Wale et al. (2009) by a more accurate delineation of the lake shore and are used in this study.

\section{The HBV-96 model}

For stream flow simulation the HBV-96 model has been selected that has many applications in operational and strategic water management. Applications are known for lumped model domains (see Seibert, 1997) and semi distributed model domains (see Booij, 2005) and commonly aim at simulating the rainfall-runoff relation. The model is classified as a conceptual water balance based model and relies on simple approximations to simulate mass exchange processes of the hydrological cycle. Input requirements to the model are precipitation, temperature and potential evapotranspiration. In this study the HBV-96 model version (Lindström et al., 1997) is used with a simulation time step of one day. Four routines which are a precipitation accounting routine, a soil moisture routine, a quick runoff routine and a base flow routine are active and transform excess water from the soil moisture zone to local runoff (see Fig. 2).

The soil moisture routine controls the formation of direct and indirect runoff. Direct runoff occurs if the simulated soil moisture storage (SM), as conceptualised through a soil moisture reservoir representing the unsaturated soil, exceeds the maximum soil moisture storage denoted by parameter FC. Otherwise, all precipitation infiltrates (IN) the soil moisture reservoir, seeps through the soil layer or evapotranspires. The seepage through the soil layer causes indirect runoff $(R)$ that is determined through a power relationship with parameter BETA as shown in Eq. (3) and the amount of infiltrating water and the soil moisture storage:

$R=\mathrm{IN}\left(\frac{\mathrm{SM}}{\mathrm{FC}}\right)^{\mathrm{BETA}}$.

This indicates that indirect runoff increases with increasing soil moisture storage but also that indirect runoff reduces to zero in case infiltration becomes zero. Actual evapotranspiration $\left(E_{\mathrm{a}}\right)$ depends on the measured potential evapotranspiration $\left(E_{\mathrm{p}}\right)$, the soil moisture storage in the reservoir and a parameter LP which is a limit above which evapotranspiration reaches its potential value. This is shown in Eqs. (4) and (5).

$$
\begin{aligned}
& E_{\mathrm{a}}=\frac{\mathrm{SM}}{\mathrm{LP} \cdot \mathrm{FC}} \cdot E_{\mathrm{p}} \quad \text { if } \mathrm{SM}<(\mathrm{LP} \cdot \mathrm{FC}) \\
& E_{\mathrm{a}}=E_{\mathrm{p}} \quad \text { if } \mathrm{SM} \geq(\mathrm{LP} \cdot \mathrm{FC})
\end{aligned}
$$

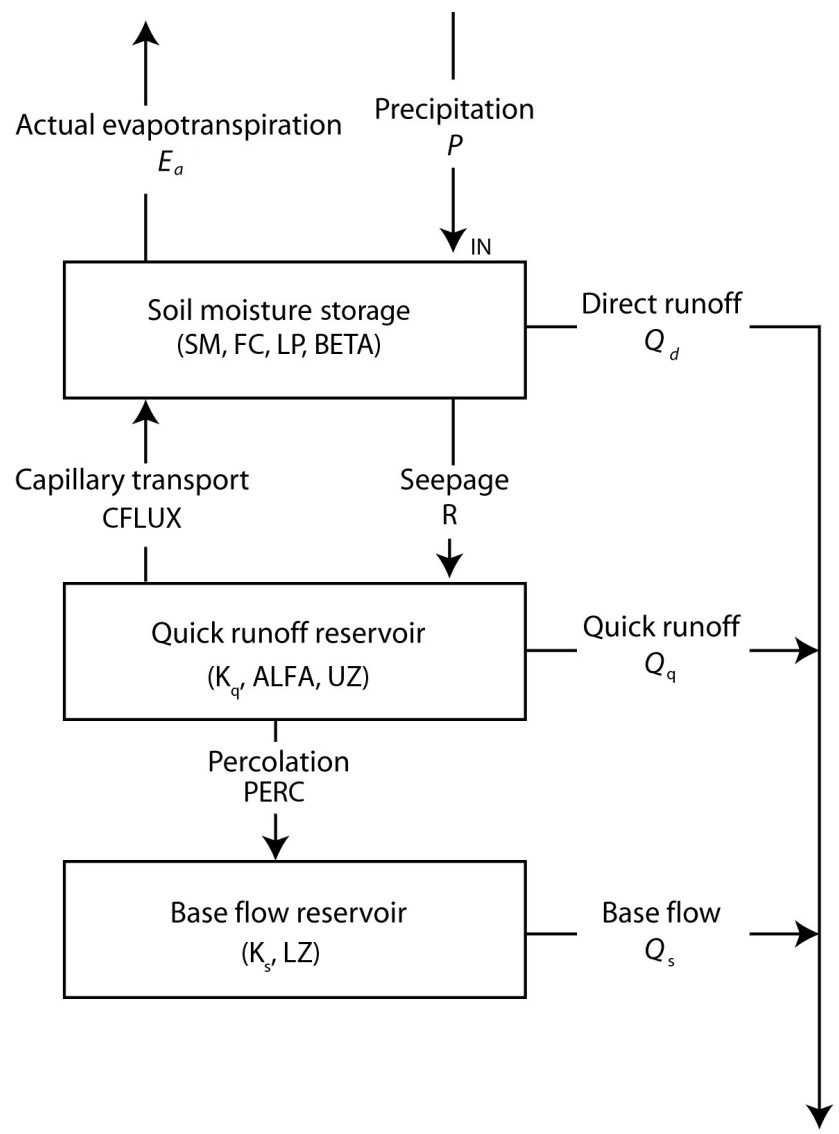

Fig. 2. A diagram of the HBV-96 approach (modified after Lindström, 1997).

At the quick runoff routine three components are distinguished which are percolation to the base flow reservoir, capillary transport to the soil moisture reservoir and quick runoff. Percolation is denoted through parameter PERC which is a constant percolation rate that occurs when water is available in the quick runoff reservoir. Capillary transport is a function of the maximum soil moisture storage, the soil moisture storage and a maximum value for capillary flow (CFLUX) as shown in Eq. (6).

$C_{\mathrm{f}}=\operatorname{CFLUX} \cdot\left(\frac{\mathrm{FC}-\mathrm{SM}}{\mathrm{FC}}\right)$

If the yield from the soil moisture routine is higher than the percolation, then water becomes available for quick flow which is shown by Eq. (7).

$Q_{\mathrm{q}}=K_{\mathrm{q}} \cdot \mathrm{UZ}^{(1+\mathrm{ALFA})}$

where UZ is the storage in the quick runoff reservoir, ALFA a measure for the non-linearity of the flow in the quick runoff reservoir and $K_{\mathrm{q}}$ a recession coefficient.

The slow flow of the catchment is generated in the base flow routine through Eq. (8).

$Q_{\mathrm{s}}=K_{\mathrm{s}} \cdot \mathrm{LZ}$ 
where $\mathrm{LZ}$ is the storage in the base flow reservoir and $K_{\mathrm{S}}$ a recession coefficient.

\section{Methodology}

The regionalisation approach selected for this study encompasses the following steps. First the HBV-96 model is calibrated for gauged catchments against observed discharges to establish good performing parameters sets to simulate catchment runoff. Next, relationships are established between the model parameters (MPs) and Physical Catchment Characteristics (PCCs) to develop the so called "regional model". This model is used to establish model parameters for ungauged catchments where MPs are defined based on the PCCs from the ungauged catchments. Then the HBV-96 model is used to simulate the runoff from the ungauged catchments. Finally, the water balance of Lake Tana is solved by considering all inflows and outflows and the closure term is calculated by comparing observed to simulated water levels. In the following subsections a description of the procedure is presented. A split sample test is applied to differentiate for periods of calibration (1994-2000) and validation (2001-2003) for the gauged catchments.

\subsection{Model calibration}

In this study model calibration is by a Monte Carlo Simulation (MCS) procedure. MCS is a technique where numerous model simulations are executed by randomly generated model parameter values with the objective to find the best performing parameter sets. Such set yields a minimum or maximum value for selected objective function(s). Good performing parameter sets are selected for further use and unsatisfactory performing sets are denied for further use. Critical in MCS is the selection of the prior parameter space, the determination of the number of simulations to be executed and the selection of the objective function(s). For details on MCS simulation reference is made to Beven and Binley (1992); Harlin and Kung (1992) and Seibert (1999).

\subsection{Parameter space}

For selection of calibration parameters for MCS, a manual model sensitivity analysis is performed and literature on applications of HBV-96 is reviewed. Studies for instance by Diermanse (2001), Lidén and Harlin (2000), Seibert (1999) Hundecha and Bárdossy (2004) indicate model sensitivity to selected parameters. Selection of prior parameter space for MCS is based on studies by (Seibert, 1997; Booij, 2005; SMHI, 2006; de Vos and Rientjes, 2007; Wale et al., 2009). In Table 1 parameter ranges for selected parameters are given.

In MCS parameter values are randomly and independently sampled from uniform distributions. Principle to the validity of MCS is that the entire parameter space is examined to allow statistical evaluation of the results. Therefore, in this study we tested the performance of the model when the number of runs was systematically increased from 1000 to 100000 and found that after 60000 runs model performance could not be further improved. In the procedure the $10 \%$ of the best performing parameters sets are selected for further analysis. From this subset minimum and maximum parameter values for each parameter are defined and the MCS procedure of 60000 runs is repeated for the newly defined parameter space. The optimally performing parameter set now is defined by averaging the parameter values of the best performing 25 parameter sets. The procedure is applied to all gauged catchments and for each catchment an optimal parameter set is defined. For assessing reliability of the parameter estimates the entire MCS procedure is repeated 15 times and optimised parameter values for each of the catchments are compared. The comparison also is performed for single best parameter sets and serves to evaluate robustness of the procedure by comparing the averaged parameter values to the single best values.

\subsection{Objective functions}

In runoff model calibration the objective commonly is to optimise parameter sets to match simulated stream flow to observed stream flow. Goodness of fit commonly is evaluated by visual inspection but also by use of objective functions that highlight selected aspects of the hydrograph such as low flows, high flows, the overall shape of a hydrograph or the rising limp of a hydrograph (see de Vos and Rientjes, 2007, 2008). Also the volumetric error is often addressed and indicates the mismatch between the volumes of runoff over the entire simulation period. In this work we selected two objective functions that indicate the overall fit of the stream flow hydrograph and the volumetric errors. For the first objective we selected the Nash-Sutcliffe (NS) efficiency criterion (Nash and Sutcliffe, 1970) and for the second objective we selected the Relative Volumetric Error (RVE). The NS objective function requires maximisation and reads:

$$
\mathrm{NS}=1-\frac{\sum_{i=1}^{n}\left(Q_{\mathrm{sim}, \mathrm{i}}-Q_{\mathrm{obs}, i}\right)^{2}}{\sum_{i=1}^{n}\left(Q_{\mathrm{obs}, i}-\overline{Q_{\mathrm{obs}}}\right)^{2}}
$$

where $\overline{Q_{\text {obs }}}$ is mean of observed flow, $Q_{\text {sim }}$ is simulated flow, $Q_{\text {obs }}$ is observed flow, $i$ is time step, $n$ is total number of time steps used during the calibration. NS can range between $-\infty$ and 1 where the value of 1 indicates a perfect fit. NS values between 0.6 and 0.8 indicate fair to good performance. A model is often said to perform very good when values are in between 0.8 and 0.9 . We note that interpreting NS values 
Table 1. Prior parameter ranges.

\begin{tabular}{lcccclllc}
\hline $\begin{array}{l}\text { Parameter } \\
\text { Unit }\end{array}$ & $\begin{array}{c}\text { FC } \\
(\mathrm{mm})\end{array}$ & $\begin{array}{c}\text { BETA } \\
(-)\end{array}$ & $\begin{array}{c}\text { CFLUX } \\
(\mathrm{mm})\end{array}$ & $\begin{array}{l}\text { LP } \\
(-)\end{array}$ & $\begin{array}{l}\text { ALFA } \\
(-)\end{array}$ & $\begin{array}{l}\left.K_{\mathrm{q}}-1\right) \\
\left(\mathrm{day}^{-1}\right)\end{array}$ & $\begin{array}{l}K_{\mathrm{S}} \\
\left(\text { day }^{-1}\right)\end{array}$ & $\begin{array}{c}\text { PERC } \\
\left(\mathrm{mm} \mathrm{day}^{-1}\right)\end{array}$ \\
\hline Minimum & 100 & 1 & 0 & 0.1 & 0.1 & 0.0005 & 0.0005 & 0.1 \\
Maximum & 800 & 4 & 2 & 1 & 3 & 0.15 & 0.15 & 2.5 \\
\hline
\end{tabular}

is not straightforward and reference is made to Schaefli and Gupta (2007). The RVE requires minimisation and reads:

$\operatorname{RVE}=\left(\frac{\sum_{i=1}^{n} Q_{\text {sim }, i}-Q_{\mathrm{obs}, i}}{\sum_{i=1}^{n} Q_{\mathrm{obs}, i}}\right) \times 100 \%$

RVE may range between $-\infty$ to $+\infty$ but indicates an excellent performing model when a value of 0 is generated. An error between $+5 \%$ and $-5 \%$ indicates a well performing model while error values between $+5 \%$ and $+10 \%$ or between $-5 \%$ and $-10 \%$ indicate reasonable performance.

\subsection{Selection of optimum parameter set}

In the procedure of parameter set selection both objective functions are combined in a single objective function and performance of the model is assessed for the objective function that suggest best model performance. The procedure is after Deckers et al. (2010) where four objective functions are combined. Comparatively, in this work we excluded NS objective functions for high flows and low flows since results in Deckers et al. (2010) indicated that best performing parameter sets mostly are found by the NS or RVE objective functions. In the procedure for each parameter set both objective functions are calculated and compared. To evaluate which objective function indicates best performance, the value of each criterion was scaled over the range of objective function values by the 60000 model runs. The NS value was scaled based on its minimum and maximum value:

$C_{\mathrm{NS}, k, n}^{\prime}=\frac{C_{\mathrm{NS}, k, n}-\min \left(C_{\mathrm{NS}, k, n_{\mathrm{tot}}}\right)}{\max \left(C_{\mathrm{NS}, k, n_{\mathrm{tot}}}\right)-\min \left(C_{\mathrm{NS}, k, n_{\mathrm{tot}}}\right)}$

where $C_{\mathrm{NS}}$ is value for the NS criterion, $k$ indicates a specific catchment, $n$ is calibration run number, $n_{\text {tot }}$ is run number.

Since RVE varies between $-\infty$ and $+\infty$ positive values as well as negative values can occur. The RVE scaling equation reads:

$C_{\mathrm{RVE}, k, n}^{\prime}=\frac{\left|C_{\mathrm{RVE}, k, n}\right|-\max \left|C_{\mathrm{RVE}, k, n_{\mathrm{tot}}}\right|}{\min \left|C_{\mathrm{RVE}, k, n_{\mathrm{tot}}}\right|-\max \left|C_{\mathrm{RVE}, k, n_{\mathrm{tot}}}\right|}$

where $C_{\mathrm{RVE}}$ is value for the RVE criterion while other terms are as defined above.
After scaling of NS and RVE, the lowest value of the two was selected for each calibration run:

$C_{k, n}^{\prime}=\min \left\{C_{\mathrm{NS}, k, n}^{\prime}, C_{\mathrm{RVE}, k, n}^{\prime}\right\}$

where $C^{\prime}$ is scaled value of the criteria.

The optimum parameter set for each catchment is now determined by selecting the highest values of all selected minimum values as determined through Eq. (14):

$C_{k}=\max \left\{\min \left(C_{k, n_{\text {tot }}}^{\prime}\right)\right\}$

It is noted that the procedure does not aim at selecting a parameter set with a highest possible objective function value but aims to select a well performing parameter set by averaging over the 25 best performing sets. This procedure aims to prevent that outliers in parameter space may cause very high objective function values and refer to Beven and Binley (1992) and Harlin and Kung (1992). Such parameter values only have limited validity and must not be considered representative. Parameter values therefore are not suitable for establishing the regional model.

\subsection{Establishing the regional model}

For developing a regional model the aim is to establish hydrological relationships between MPs and PCCs. PCCs in this respect are characteristics of the catchment that relate to morphology, geometry, topography, climate, soils and land use. Selected PCCs should directly or indirectly affect the production of runoff in a catchment and as such selection is a critical step. In this work some 22 PCCs are selected from various sources. PCCs that relate to topography, geometry and the morphology of the catchments are extracted from the SRTM DEM. The PCCs under Land Use and Geology and Soil are obtained from the land use and soil map as described in Sect. 3. PCCs under Climate are from the meteorological data as made available by NMA. Table 2 shows the list of PCCs selected for this study.

Knowledge on the relations between HBV MPs and the PCCs allows us to estimate MPs for ungauged catchment systems when the PCCs from these catchments are known. To set up a regional model for estimation of model parameters in ungauged catchments, often regression analysis are applied (see Bastola et al., 2008; Heuvelmans et al., 2006; Kim et al., 2008; Xu, 2003; Deckers et al., 2010). Such analysis is selected for this study as well. It is noted that not all 
Table 2. Selected physical catchment characteristics (PCCs).

\begin{tabular}{|c|c|c|}
\hline Group & PCC & Description and Unit \\
\hline $\begin{array}{l}\text { Morphology, } \\
\text { Topography }\end{array}$ & $\begin{array}{l}\text { AREA } \\
\text { LFP } \\
\text { MDEM } \\
\text { HI } \\
\text { AVGSLOPE } \\
\text { SHAPE } \\
\text { CI } \\
\text { EL } \\
\text { DD }\end{array}$ & $\begin{array}{l}\text { Catchment area }\left(\mathrm{km}^{2}\right) \\
\text { Longest flow path }(\mathrm{km}) \\
\text { DEM mean }(\mathrm{m}) \\
\text { Hypsometric integral }(-) \\
\text { Average slope of catchment }(\%) \\
\text { Catchment shape }(-) \\
\text { Circularity index }(-) \\
\text { Elongation ratio }(-) \\
\text { Drainage Density }\left(\mathrm{m} \mathrm{km}^{-2}\right)\end{array}$ \\
\hline Land use & $\begin{array}{l}\text { CROPD } \\
\text { CROPM } \\
\text { GL } \\
\text { URBAN } \\
\text { FOREST }\end{array}$ & $\begin{array}{l}\text { Cultivated Dominantly (\%) } \\
\text { Cultivated Moderately (\%) } \\
\text { Grassland (\%) } \\
\text { Urban }(\%) \\
\text { Forest }(\%)\end{array}$ \\
\hline $\begin{array}{l}\text { Geology } \\
\text { and Soil }\end{array}$ & $\begin{array}{l}\text { LEP } \\
\text { NIT } \\
\text { VER } \\
\text { LUV }\end{array}$ & $\begin{array}{l}\text { Leptosol area }(\%) \\
\text { Nitosol area }(\%) \\
\text { Vertisol area }(\%) \\
\text { Luvisol area }(\%)\end{array}$ \\
\hline Climate & $\begin{array}{l}\text { SAAR } \\
\text { PWET } \\
\text { PDRY } \\
\text { PET }\end{array}$ & $\begin{array}{l}\text { Standard annual average } \\
\text { rainfall (mm) } \\
\text { Mean precipitation wet } \\
\text { season (Jun to Sep) (mm) } \\
\text { Mean precipitation dry } \\
\text { season (Oct to May) (mm) } \\
\text { Mean annual } \\
\text { evapotranspiration (mm) }\end{array}$ \\
\hline
\end{tabular}

relationships of regional models in these studies are hydrologically meaningful although relationships are statistically significant.

\subsection{Regression analysis}

Multiple linear regression is performed for each model parameter. Statistical significance and strength are tested to guarantee that regression equations can be used. Also the correlation $(r)$ is tested by the t-test (Eq. 15).

$t_{\text {cor }}=\frac{|r| \sqrt{n-2}}{\sqrt{1-r^{2}}}$

where, $t_{\text {cor }}$ is $t$ value of the correlation, $r$ is correlation coefficient, $n$ is sample size.

The following hypothesis is tested. The null hypothesis $H_{0}$ and the specific hypothesis $H_{1}$ are:

$H_{0}$ : the correlation between the PCC and MPs is zero, $\rho=0$.

$H_{1}$ : the correlation between the PCC and MPs is not zero, $\rho \neq 0$.

If $t_{\mathrm{cor}}>t_{\mathrm{cr}}$ the null-hypothesis is rejected (MPs are associated with PCCs in the population).
To determine the critical value $t_{\mathrm{cr}}$ the number of degree of freedom, df, and $\alpha$, a number between 0 and 1 to specify the confident level has to be determined. In this study a significant level of $\alpha=0.1$ is chosen that is applied to a two-tail test with $n$-2 degree of freedom. Using this information, for $t_{\mathrm{cr}}$ a value of 2.132 is found (critical value from $t$ distribution table). To determine at what $r$ value the hypothesis is rejected the test statistic is solved. An $r$ of 0.72 was established and thus $r$ greater than 0.72 and smaller than -0.72 results in a statistically significant relationship.

The second method applied is based on multiple regression analysis to optimize the relationship with the forward selection and with the backward removal method. Multiple linear regression is used to predict MPs from several independent PCCs. In the forward entry approach the initially established regression model that incorporates the most significant PCC is extended by entering a second independent variable in the regional model. This step is accepted if the entry statistic (i.e. significance level, $\alpha$ ) of both independent variables is not exceeded. The statistical tools are used to select the independent variable that adds most significance to the relation. Additional steps are executed until the last added independent variable does not significantly contribute to the regression model. In addition to the forward entry method also the backward removal method is applied. In this method all expected PCCs are entered into the model. Based on the removal statistic (i.e. significance level, $\alpha$ ) independent variables are stepwise removed from the model. The significance of the multiple linear regression equations is tested by evaluating the significance of individual coefficients and by a test of overall significance. First a hypothesis test is applied to determine if the regression equation is significant. For such test it is assumed that the error term, $\varepsilon$, is not correlated and normally distributed. Further the error term must have an average of zero and a constant variance. In this study these assumptions are made and two hypothesis tests are executed to evaluate the significant of the regression equation. Those are the null-hypothesis and the specific hypothesis. Further the strength of the determined regression equation is evaluated by the coefficient of determination, $r^{2}$.

\subsection{Validation of the regional model}

Prior to its use a regional model must be tested where predicted and observed discharges are compared for a subset of gauged catchments that were not used when establishing the regional model. Such a proxy basin test (see Klemeš, 1986) is commonly applied when a large number of catchments is available (e.g. Merz and Blöschl, 2004; Young, 2006) but is denied in this study by the small number of gauged catchments available in the Lake Tana basin. Instead we applied a split sample test where the regional model is tested for the same catchments that were used for establishing the regional model but for a different period in time (2001-2003). 


\subsection{Lake level simulation}

For simulation of daily lake level fluctuations the following water balance equation is solved:

$\frac{\Delta S}{\Delta T}=P-E_{\mathrm{vap}}+Q_{\text {gauged }}+Q_{\text {ungauged }}-Q_{\mathrm{BNR}}$

where $\Delta S / \Delta T$ denotes the change in storage over time, $P$ is Lake areal rainfall, $E_{\text {vap }}$ is open water evaporation, $Q_{\text {gauged }}$ is Gauged river inflow, $Q_{\text {ungauged }}$ is Ungauged river inflow and $Q_{\mathrm{BNR}}$ is the Blue Nile River outflow (all terms in $\mathrm{Mm}^{3}$ day $^{-1}$ ).

For estimating lake evaporation the Penman-combination equation is selected where albedo was estimated using the Moderate Resolution Imaging Spectroradiometer (MODIS) Level 1b product (http://ladsweb.nascom.nasa. gov/data/search.html). Albedo is calculated from channels 1 to 7 by integrating band reflectance across the shortwave spectrum. Images require geometric, radiometric and atmospheric correction and the radiance at the top of the atmosphere needs to be known. During integration, weighting coefficients are applied that represent the fraction of surface solar radiation occurring within the spectral range as represented by a specific band. We refer to Liang (2001) and Liang et al. (2002) for extensive descriptions.

For the years 2000 and 2002 only some 14 and 16 cloud free images could be acquired, respectively. For days images are not available, albedo values are estimated by interpolating albedo values between 2 subsequent acquisition days. Daily averaged values are defined by averaging the two albedo values and as such daily albedo maps are generated for Lake Tana. A lake averaged albedo is estimated by averaging over all pixels that have spatial resolution of $1 \mathrm{~km}^{2}$. To estimate the lake evaporation, meteorological data from Bahir Dar station is used since out of the available stations only this station is located close to Lake Tana. Daily rainfall over Lake Tana is estimated on daily base by spatial interpolation of gauge data from Bahir Dar, Chawhit, Zege, Deke Estifanos and Delgi station (see Fig. 1). We selected a weight power of 2 to allow representation of the relatively high spatial variability of rainfall in the basin (see Haile et al., 2009, 2010, 2011b).

For calculation of stream flow from gauged systems, observed stream flow time series are directly used in the water balance. Runoff time series are screened and corrected and analysis indicated that not all time series are reliable (see Sect. 3). For instance, results indicated that some gauges were relocated over time while other gauges indicated inundation during periods of extreme rainfall. For some gauges erroneous observations are identified by double mass curve analysis. Erroneous data is corrected by analyzing the ratio of incremental differences for consecutive days for rainfall and runoff for the respective catchments. Outliers serve to identify errors and difference between consecutive rainfall, or discharge observations serve to correct for erroneous discharges or rainfall, respectively. The lake inflow from ungauged systems is estimated by the regionalization approach as described in Sect. 5.2.

Time series for the Lake outflow by Abay River are directly entered in the water balance equation after time series of outflow are corrected for consistency by use of a newly established stage-discharge relation in Wale et al. (2009).

In this study it is assumed that the groundwater system is decoupled from the lake and any lake leakage is ignored in the balance. We note that in (Kebede et al., 2006) lake leakage is estimated to be some $7 \%$ of the total annual lake budget. However, in Chebud and Melesse (2009), numeric groundwater modeling is applied and results indicate that lake leakage is unlikely and therefore exchange of water between the lake and the groundwater system is ignored in the water balance calculations in this study.

\section{Results and discussion}

\subsection{Gauged systems}

Results of MCS are shown in Table 3. For each of the catchments optimal parameter sets are identified and objective function values for the optimized parameter set are calculated. Results of NS for calibration and validation indicate relatively high values for the 6 catchments with a highest calibration value of 0.85 for the Gilgel Abay catchment. The results of calibration are not satisfactory for Gumero $\left(163 \mathrm{~km}^{2}\right)$, Garno $\left(98 \mathrm{~km}^{2}\right)$ and Gelda $\left(26 \mathrm{~km}^{2}\right)$. All three catchments have low NS values $(<0.41)$ while RVE values are relatively high. Therefore the use of these catchments is ignored when establishing the regional model. Wale et al. (2009) suggested that the time of concentration, which is defined as the time period for water to travel from the most remote point in the catchment to the outlet, is small. Therefore quick runoff responses often are not observed by the daily observations and also difficult to represent by the daily simulation time step. Further, some gauging stations are not placed at the catchment outlet but at a location upstream of the outlet that has easy road access. As such the runoff as observed does not indicate the catchment runoff and rainfallrunoff time series that are assumed to be representative for the respective catchments cannot be considered reliable since it is not clear which parts of the catchments are drained.

Table 3 indicates that some parameters have a relatively large value range across the six catchments. This suggests that the Lake Tana basin can be characterized by relatively large variability with respect to climatic, topographic and physiographic properties. We note that the number of gauged catchments selected for regionalization only is small (i.e., 6). Most regionalisation studies rely on a much larger number of catchments as the basins are much larger than the Lake Tana basin. For instance, in Merz and Blöschl (2004) some 308 catchments were used; Sefton and Howarth (1998) used 
Table 3. Optimized model parameters for gauged catchments (1994-2000).

\begin{tabular}{lrrrrrrrrr}
\hline & Ribb & Gilgel Abay & Gumara & Megech & Koga & Kelti & Gumero & Garno & Gelda \\
\hline FC & 309 & 434 & 349 & 193 & 730 & 196 & 469 & 221.25 & 141.14 \\
BETA & 1.23 & 2.08 & 1.31 & 1.56 & 1.34 & 1.60 & 1.10 & 2.58 & 1.20 \\
LP & 0.73 & 0.63 & 0.87 & 0.71 & 0.42 & 0.62 & 0.26 & 0.23 & 0.86 \\
ALFA & 0.31 & 0.24 & 0.25 & 0.29 & 0.41 & 0.28 & 1.08 & 0.27 & 0.51 \\
$K_{\mathrm{q}}$ & 0.07 & 0.08 & 0.03 & 0.03 & 0.07 & 0.03 & 0.03 & 0.10 & 0.003 \\
$K_{\mathrm{S}}$ & 0.10 & 0.09 & 0.07 & 0.09 & 0.05 & 0.10 & 0.13 & 0.11 & 0.15 \\
PERC & 1.09 & 1.02 & 1.44 & 1.47 & 1.63 & 1.53 & 2.32 & 1.61 & 1.41 \\
CFLUX & 0.60 & 1.09 & 0.72 & 0.79 & 0.74 & 0.83 & 0.39 & 1.35 & 1.00 \\
\hline & & & & Calibration & & & & \\
\hline NS & 0.78 & 0.85 & 0.72 & 0.61 & 0.67 & 0.66 & 0.16 & 0.33 & 0.41 \\
RVE \% & -1.61 & -0.35 & -2.44 & 2.91 & -0.06 & -2.00 & 18.51 & 34.02 & -23.16 \\
\hline & & & & Validation & & & & - \\
\hline NS & 0.87 & 0.85 & 0.79 & 0.51 & 0.65 & 0.67 & - & - & - \\
RVE \% & 3.55 & -2.32 & -9.87 & 2.87 & -9.83 & -5.30 & - & - & - \\
\hline
\end{tabular}

60 catchments; Young (2006) used 260 catchments for the entire UK; and Deckers et al. (2010) used 48 catchments also for the UK. To evaluate to what extent the small number of catchments in this study affected the regionalisation results is difficult and touches on the issue if a relatively large or small variability of catchment properties favours regionalisation. Little variation implies little hydrologic diversity and the development of robust regional model may be questioned while too much variability may result in weak relationships as suggested in (Young, 2006 and Deckers et al., 2010). Haberlandt et al. (2001) favour the assumption of large variability and a clear range of different conditions must be considered as a basis for regionalisation. Seibert (1999) and Wagener and Wheater (2006) on the other hand report on regionalisation studies where catchments are characterised by relatively little variation. For the Lake Tana basin relatively high variability of catchment properties is suggested in (Haile et al., 2009, 2011a), who indicated that large topographic variability directly affected the rainfall patterns. To asses variability we normalised PCC values for gauged and ungauged catchments by their area averaged values. Analysis indicates that normalised values of most PCCs for the gauged and the ungauged catchments only change by some 20 to $30 \%$. For the group of soils, normalised differences are large and range between 0.02 and 5.84 while differences for climate PCCs are smallest with many values around 1.0 and a value range of 0.70-1.24. Larger differences are observed for the morphologic and topographic PCCs where most values are in between 0.6 and 1.4 with value ranges $0.35-2.25$. For land use related PCCs normalised values show largest variability but also values ranges are largest (i.e., between 0.01 and 6.41). Analysis of PCCs used in the regional model show a similar pattern. Morphology, topography and climate related
PCCs indicate smallest variability while the soils and land use PCCs indicate largest variability. To become more conclusive how Lake Tana basin variability affects the results of regionalization is difficult. For this study inter catchment variability by topographic, morphologic and climatic PCCs is smallest but, particularly, these PCCs are mostly used in the regional model. Critical remains if the use of only six catchments is sufficient to represent catchment variability for constructing the regional model. To further assess how variability is represented in relation to the number of catchments used is left for further research. We presume that, in principle, for such analysis a much larger number of gauged catchments are required. As described in Sect. 5.2, after finishing the first MCS calibration run of 60000 model simulations for the posterior parameter ranges we tested the consistency of the parameter estimates by additional MCS runs. Figure 3 shows results for $15 \mathrm{MCS}$ calibration runs of 60000 each. The results indicate that in each MCS run the averaged values of the 25 best performing parameter sets differ and therefore different optimal parameter sets are identified. Results suggest that the most optimal parameter set probably cannot be defined uniquely but values somehow converge to an optimal value. Therefore the optimum parameter set is selected by taking the average of the 15 parameter values. Results suggest that for optimal parameter selection an extreme high number of model runs is required. MCS studies often rely on less than 50000 runs but results of this study indicate the weaknesses of such procedure. The procedure of $15 \mathrm{MCS}$ runs of 60000 each is applied to all catchments and optimum parameter sets are established. We note that for the Gilgel Abay catchment different optimum parameter sets are obtained as compared to Uhlenbrook et al. (2010) who applied 1000000 runs. Possible reasons for the differences is that we 

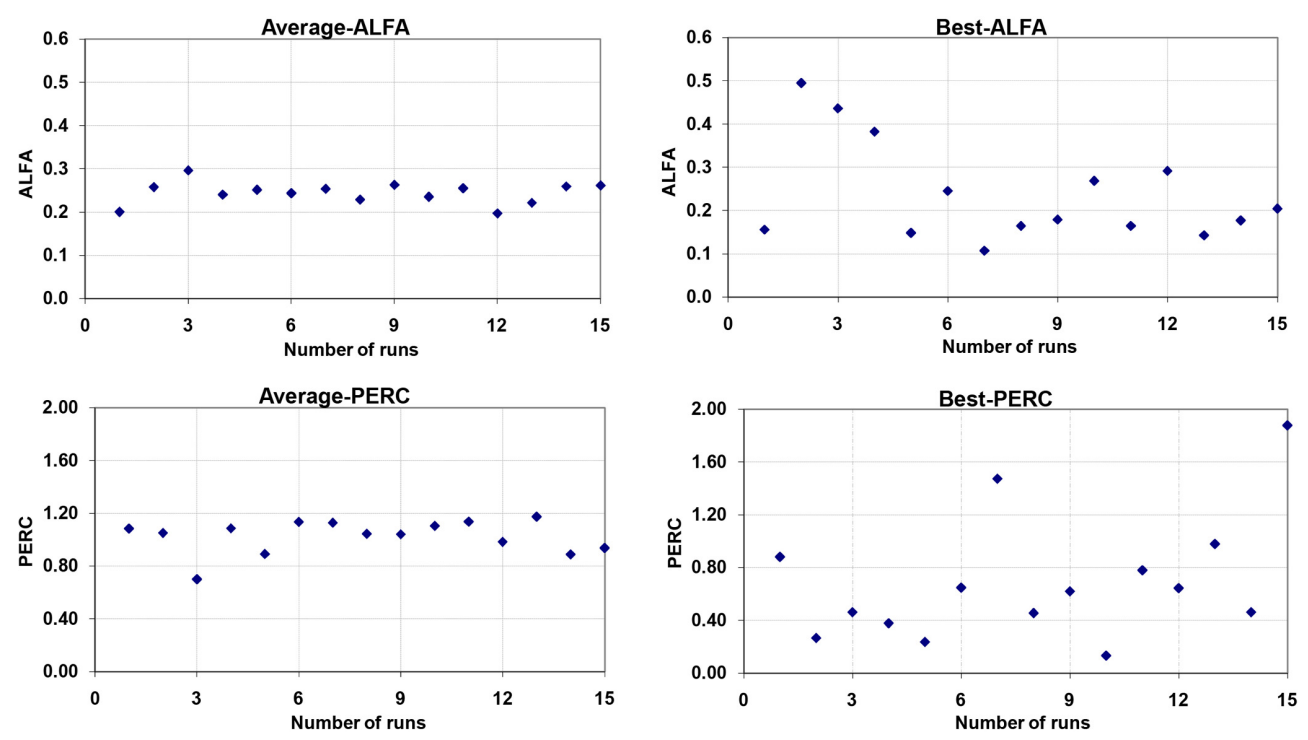

Fig. 3. Left hand side shows the average parameter values the 25 best performing parameter sets for ALFA and PERC for each MCS run of 60000 runs each. The right hand side shows single best parameter values.

present average values of 25 best performing sets of 15 independent MCS runs, that a slightly different model structure is applied but also that slightly different prior parameter ranges are different. We further note that again different optimum values are found as compared to Abdo et al. (2009) and Wale et al. (2009) who applied manual calibration.

Figure 4 shows the Box and Whisker plots of parameters standardized by the prior range used for Monte Carlo Simulations (Gilgel Abay catchment). The boxes depict the median and upper and lower quartiles. The whiskers indicate the most extreme values. The interquartile value ranges for ALFA are smallest and suggest that values are identified with consistency resulting in a stable region of solutions in parameter space. We note that box values of the upper and lower quartiles are relatively small and suggest that small ALFA values favour a good performing model. The result also suggests high model sensitivity to ALFA and thus optimum values for the calibrations runs are well defined. FC shows relatively narrow interquartile box ranges and suggest that the model is quite sensitive to changes of FC. The remaining parameters have comparatively, equally large interquartile ranges and indicate lower sensitivity as compared to ALFA and FC. The whiskers indicate that distributions are not skewed and also suggest that the model is not highly sensitive. We note that ALFA is a measure for the non-linearity of the flow in the quick runoff reservoir while FC directly affects seepage flow and thus the quick runoff processes. Since both parameters affect the quick runoff behaviour of the model this indicates relatively low predictive uncertainty.

Figure 5 shows the model calibration results of catchments used for developing the regional model. Table 3 also shows the model validation results for the period 2001-2003.

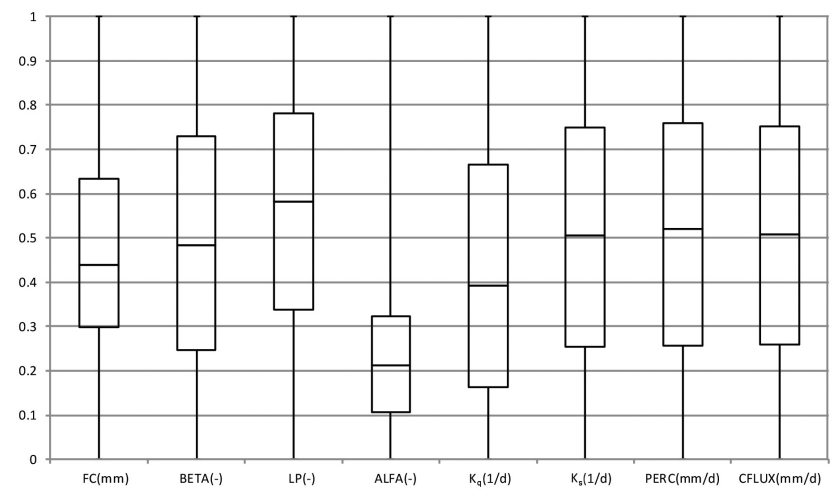

Fig. 4. Box and Whisker plots of parameters standardized by the prior range used for Monte Carlo Simulations (Gilgel Abay catchment). The boxes depict the median and upper and lower quartiles. The whiskers show the most extreme values.

Results for NS values in general slightly deteriorate as compared to the calibration results. RVE values in general are somewhat higher indicating larger errors in the water balance. Errors for NS and RVE, however, are relatively small and indicate a good to satisfactory model performance of the regional model.

\subsection{Regionalisation}

Correlations between PCCs and MPs are established to determine the significance of each relationship. In the procedure the correlation is statistically significant when the correlation coefficient is outside the critical value range of -0.72 to 0.72 (see Sect. 5.2). In Table 4 the significant correlation coefficients are highlighted. 

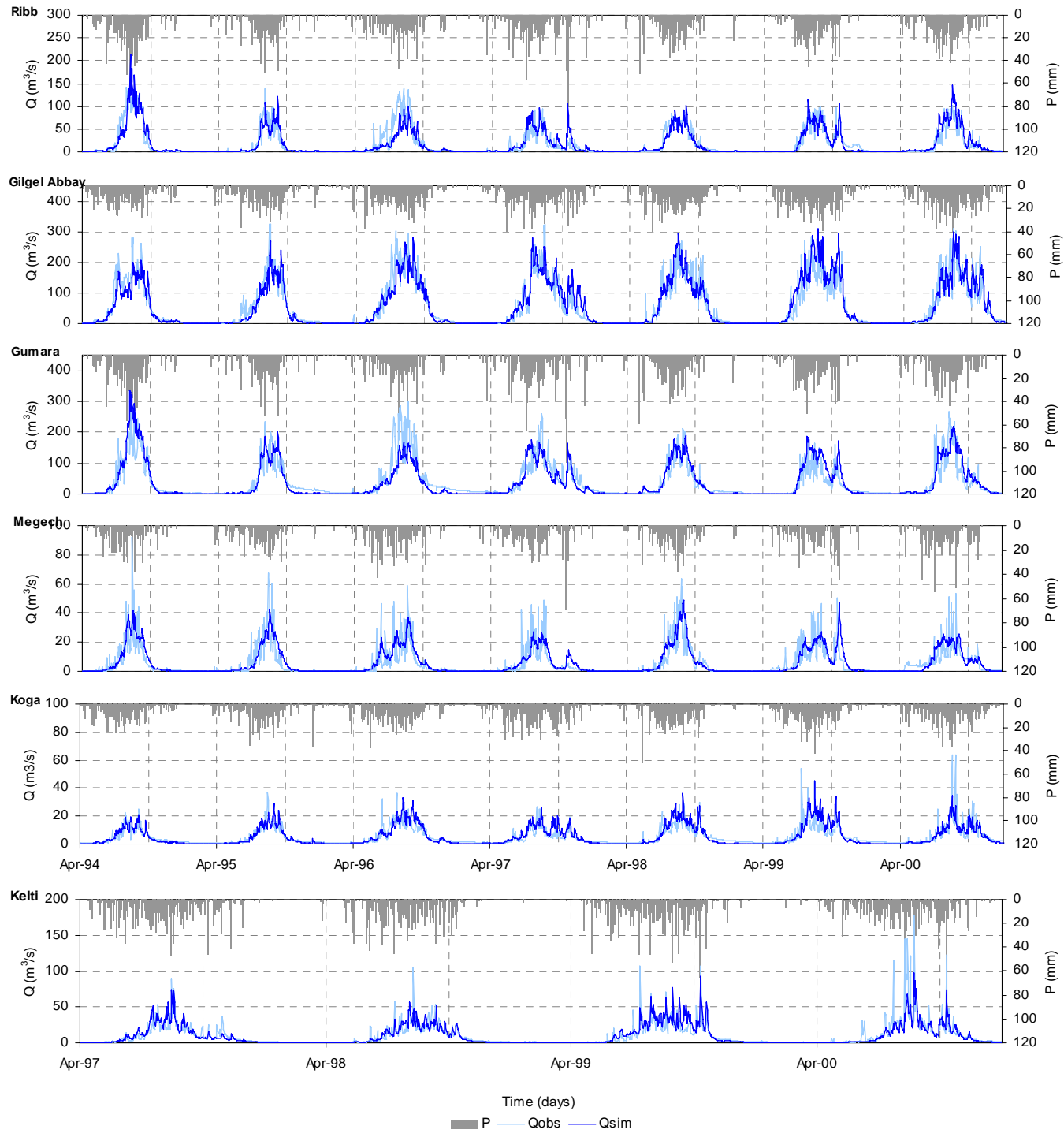

Fig. 5. Model calibration results of Ribb, Gilgel Abay, Gumara, Megech, Koga (1994-2000) and Kelti (1997-2000) catchments.

It is assumed that by use of multiple PCCs a better relation can be established than when only one PCC is used. Therefore relations between PCCs and MPs are assessed through multiple linear regression analysis. This is done by the forward entry method and the backward removal method as described in Sect. 5.2. The established regional model is shown in Table 5 and is followed by a description of each parameter.

FC: in this study FC showed positive correlation with $\mathrm{CI}$ and negative correlation with $\mathrm{HI}$ and DD. The highest correlation is with $\mathrm{HI}$ that is a measure of the distribution of elevation in a catchment and is defined as the average elevation a.m.s.l. minus the minimum divided by the difference between the maximum and minimum elevation a.m.s.l. The forward entry method was executed with $\mathrm{HI}$ as initial variable and results indicated that there was no other variable that could improve the strength of the relation. Therefore the procedure was terminated and the regression equation is determined with only HI with $R^{2}$ of $66.3 \%$. The statistical characteristics are shown in Table 5. We note that from a hydrological perspective the relation between FC and HI may be questioned since FC reflects on soil properties while $\mathrm{HI}$ reflects on catchment topography and geometry.

BETA: in this study, BETA is negatively correlated to SHAPE and positively correlated to CROPD. As the highest correlation is with SHAPE, the forward entry method is executed including SHAPE as the initial variable. SHAPE is defined as the difference between the maximum and minimum elevation a.m.s.l. divided by 
Table 4. Correlation matrix between model parameters and PCCs for 6 selected catchments; significant correlation coefficients are in bold.

\begin{tabular}{lrrrrrrrr}
\hline & $\begin{array}{r}\text { FC } \\
(\mathrm{mm})\end{array}$ & $\begin{array}{r}\text { BETA } \\
(-)\end{array}$ & $\begin{array}{r}\text { LP } \\
(-)\end{array}$ & $\begin{array}{r}\text { ALFA } \\
(-)\end{array}$ & $\begin{array}{r}K_{\mathrm{q}} \\
\left(1 \mathrm{~d}^{-1}\right)\end{array}$ & $\begin{array}{r}K_{\mathrm{S}} \\
\left(1 \mathrm{~d}^{-1}\right)\end{array}$ & $\begin{array}{r}\text { PERC } \\
\left(\mathrm{mm} \mathrm{d}^{-1}\right)\end{array}$ & $\begin{array}{r}\text { CFLUX } \\
\left(\mathrm{mm} \mathrm{d}^{-1}\right)\end{array}$ \\
\hline AREA & -0.18 & -0.01 & 0.49 & $-\mathbf{0 . 7 7}$ & 0.13 & 0.62 & $-\mathbf{0 . 8 2}$ & 0.07 \\
LFP & -0.17 & -0.15 & 0.53 & -0.51 & 0.25 & 0.52 & $-\mathbf{0 . 7 4}$ & -0.16 \\
MDEM & 0.04 & -0.58 & 0.33 & -0.64 & -0.11 & 0.66 & -0.51 & -0.51 \\
HI & $-\mathbf{0 . 8 1}$ & -0.03 & $\mathbf{0 . 7 7}$ & $-\mathbf{0 . 7 6}$ & -0.44 & $\mathbf{0 . 7 7}$ & -0.44 & -0.07 \\
AVGSLOPE & -0.30 & -0.48 & 0.39 & $-\mathbf{0 . 7 5}$ & -0.31 & $\mathbf{0 . 9 2}$ & -0.52 & -0.45 \\
SHAPE & 0.65 & $\mathbf{- 0 . 9 0}$ & -0.42 & 0.12 & -0.29 & -0.04 & 0.43 & $-\mathbf{0 . 8 3}$ \\
CI & $\mathbf{0 . 7 8}$ & -0.37 & -0.55 & 0.58 & 0.37 & -0.46 & 0.28 & -0.37 \\
EL & 0.54 & -0.59 & -0.32 & 0.59 & -0.01 & -0.48 & 0.57 & -0.66 \\
DD & $-\mathbf{0 . 7 4}$ & 0.23 & 0.64 & -0.35 & 0.30 & $\mathbf{0 . 7 7}$ & $-\mathbf{0 . 8 3}$ & 0.06 \\
CROPD & -0.39 & $\mathbf{0 . 7 7}$ & -0.04 & 0.35 & 0.10 & -0.36 & 0.20 & 0.69 \\
CROPM & 0.47 & -0.71 & 0.03 & -0.52 & -0.22 & 0.27 & -0.16 & -0.55 \\
GL & -0.18 & -0.54 & 0.36 & -0.19 & 0.08 & 0.61 & -0.42 & -0.67 \\
URBAN & -0.53 & -0.19 & 0.42 & -0.71 & $-\mathbf{0 . 7 2}$ & 0.59 & -0.05 & -0.13 \\
FOREST & 0.67 & -0.61 & -0.60 & 0.47 & 0.20 & -0.09 & 0.23 & -0.63 \\
LEP & -0.50 & -0.36 & 0.20 & -0.23 & -0.59 & 0.57 & 0.14 & -0.44 \\
NIT & 0.26 & -0.31 & -0.56 & 0.26 & -0.49 & -0.16 & 0.69 & -0.26 \\
VER & 0.65 & 0.07 & $-\mathbf{0 . 7 3}$ & $\mathbf{0 . 8 1}$ & 0.18 & $-\mathbf{0 . 8 8}$ & 0.71 & 0.09 \\
LUV & 0.04 & 0.40 & 0.30 & 0.15 & 0.37 & -0.55 & -0.08 & 0.38 \\
SAAR & 0.45 & 0.52 & -0.31 & 0.12 & $\mathbf{0 . 7 5}$ & -0.29 & -0.42 & 0.62 \\
PWET & 0.45 & 0.39 & -0.21 & 0.07 & $\mathbf{0 . 7 3}$ & -0.24 & -0.46 & 0.49 \\
PDRY & 0.41 & 0.69 & -0.45 & 0.20 & 0.71 & -0.36 & -0.31 & $\mathbf{0 . 8 1}$ \\
PET & -0.13 & -0.11 & -0.23 & -0.09 & -0.59 & 0.13 & 0.43 & -0.05 \\
\hline
\end{tabular}

the square root of catchment size. Results of the forward entry method showed that BETA is correlated with SHAPE and HI with $R^{2}$ of $96.02 \%$. From a hydrological point of view BETA can be related to both SHAPE and HI since BETA affects the generation of indirect runoff processes that relate to topographic characteristics. The statistical characteristics are shown in Table 5.

LP: in this study the evapotranspiration parameter LP has significant positive correlation with $\mathrm{HI}$ and negative correlation with VER that indicate poorly drained clay soils. The forward entry method is executed with highly correlated $\mathrm{HI}$ as the initial variable. This result showed that LP is correlated to $\mathrm{HI}$ and to LUV with $R^{2}$ of $91.1 \%$. LUV is \% area luvisols that are active clays with medium to high water storage capacity. From a hydrologic view point the relation between LP and LUV is much more plausible than the relation between LP and HI. The statistical characteristics are shown in Table 5.

ALFA: in this study ALFA has positive correlation with VER and negative correlation with AREA (i.e., catchment area), HI and AVGSLOPE (i.e., average slope of catchment area). For optimisation of the relation the forward entry method is executed and yielded best results with variable AREA as initial variable. We note that VER in all gauged catchments only is very small.
After adding the catchment characteristic URBAN (i.e., $\%$ urban area) the $R^{2}$ increased up to $95.1 \%$ and this regression equation is accepted. Since ALFA is a quick runoff parameter this equation appears to be plausible. Catchments are of relative small size suggesting that runoff contributions by quick runoff are directly observable in the runoff hydrograph (i.e. not smoothened by long travel times) while a small \% of urban area indicates small runoff contributions from paved areas. The statistical characteristics are shown in Table 5.

$K_{\mathrm{q}}$ : in this study the quick runoff recession coefficient $K_{\mathrm{q}}$ showed correlation with URBAN $(-0.72)$, SAAR (0.75) and PWET (0.73). The forward entry method is executed by taking SAAR (i.e., standard average annual rainfall) as the initial variable. By adding other variables the strength could not be improved and the simple relation with $R^{2}$ of $56.35 \%$ is accepted. It is noted that the relation has no physical meaning since SAAR is a climate indicator on annual base. The statistical characteristics are shown in Table 5.

$K_{\mathrm{S}}$ : In this study $K_{\mathrm{S}}$ has correlation with HI (0.77), AVGSLOPE (0.92) and VER (-0.88). The forward entry method was executed with AVGSLOPE as initial variable. The strength of the equation could not be improved by adding other variables and the simple linear 
Table 5. The regional model and its statistical characteristics.

\begin{tabular}{|c|c|c|c|c|c|}
\hline & Coefficient & $\mathrm{p}$-value & $t_{\mathrm{cal}}$ & Std error & $R^{2}$ \\
\hline \multicolumn{6}{|c|}{$\mathrm{FC}=\beta_{0}+\beta_{1} \cdot \mathrm{HI}$} \\
\hline$\beta_{0}$ & 3520.82 & 0.0351 & 3.1317 & 1124.26 & \multirow[t]{2}{*}{$66.3 \%$} \\
\hline$\beta_{1}$ & -6651.21 & 0.0487 & -2.8032 & 2372.70 & \\
\hline \multicolumn{6}{|c|}{$\mathrm{BETA}=\beta_{0}+\beta_{1} \cdot \mathrm{SHAPE}+\beta_{2} \cdot \mathrm{HI}$} \\
\hline$\beta_{0}$ & 7.551 & 0.0100 & 5.85 & 1.2918 & \multirow[t]{3}{*}{$96.02 \%$} \\
\hline$\beta_{1}$ & -8.544 & 0.0429 & -3.39 & 2.5233 & \\
\hline$\beta_{2}$ & -0.036 & 0.0034 & -8.50 & 0.0043 & \\
\hline \multicolumn{6}{|c|}{$\mathrm{LP}=\beta_{0}+\beta_{1} \cdot \mathrm{HI}+\beta_{2} \cdot \mathrm{LUV}$} \\
\hline$\beta_{0}$ & -2.2435 & 0.0258 & -4.13 & 0.5432 & \multirow[t]{3}{*}{$91.1 \%$} \\
\hline$\beta_{1}$ & 5.8697 & 0.0133 & 5.27 & 1.1141 & \\
\hline$\beta_{2}$ & 0.0027 & 0.0471 & 3.26 & 0.0008 & \\
\hline \multicolumn{6}{|c|}{$\mathrm{ALFA}=\beta_{0}+\beta_{1} \cdot \mathrm{AREA}+\beta_{2} \cdot \mathrm{URBAN}$} \\
\hline$\beta_{0}$ & 0.45233 & 0.0003 & 18.63 & 0.02428 & \multirow[t]{3}{*}{$95.1 \%$} \\
\hline$\beta_{1}$ & -0.00009 & 0.0251 & -4.17 & 0.00002 & \\
\hline$\beta_{2}$ & -0.73650 & 0.0341 & -3.71 & 0.19865 & \\
\hline \multicolumn{6}{|c|}{$K_{\mathrm{q}}=\beta_{0}+\beta_{1} \cdot \mathrm{SAAR}$} \\
\hline$\beta_{0}$ & -0.06555 & 0.3095 & -1.16 & 0.05636 & \multirow[t]{2}{*}{$56.35 \%$} \\
\hline$\beta_{1}$ & 0.00009 & 0.0855 & 2.27 & 0.00004 & \\
\hline \multicolumn{6}{|c|}{$K_{\mathrm{S}}=\beta_{0}+\beta_{1} \cdot \mathrm{AVGSLOPE}$} \\
\hline$\beta_{0}$ & 0.0187 & 0.2093 & 1.49 & 0.0125 & \multirow[t]{2}{*}{$85.25 \%$} \\
\hline$\beta_{1}$ & 0.0018 & 0.0086 & 4.81 & 0.0004 & \\
\hline \multicolumn{6}{|c|}{$\mathrm{PERC}=\beta_{0}+\beta_{1} \cdot \mathrm{DD}+\beta_{2} \cdot \mathrm{SAAR}$} \\
\hline$\beta_{0}$ & 7.4926 & 0.0088 & 6.11 & 1.2266 & \multirow[t]{3}{*}{$89.9 \%$} \\
\hline$\beta_{1}$ & -0.0128 & 0.0192 & -4.61 & 0.0028 & \\
\hline$\beta_{2}$ & -0.0005 & 0.0864 & -2.52 & 0.0002 & \\
\hline \multicolumn{6}{|c|}{$\mathrm{CFLUX}=\beta_{0}+\beta_{1} \cdot \mathrm{SHAPE}+\beta_{2} \cdot \mathrm{PDRY}+\beta_{3} \cdot \mathrm{PET}$} \\
\hline$\beta_{0}$ & -0.2184 & 0.2689 & -1.52 & 0.1441 & \multirow[t]{4}{*}{$96.27 \%$} \\
\hline$\beta_{1}$ & -0.0082 & 0.0021 & -21.86 & 0.0004 & \\
\hline$\beta_{2}$ & 0.3867 & 0.0019 & 22.63 & 0.0171 & \\
\hline$\beta_{3}$ & 0.0007 & 0.0184 & 7.28 & 0.0001 & \\
\hline
\end{tabular}

relation is accepted with $R^{2}$ of $85.25 \%$. A recession coefficient commonly relates to the catchment runoff response time where response times commonly decrease when steepness increases. The statistical characteristics are shown in Table 5.

PERC: in this study PERC has negative relation with AREA $(-0.82)$, LFP $(-0.74)$ and DD $(-0.83)$. The forward entry method was executed by adding DD (i.e., drainage density) as the first variable and after including SAAR, $R^{2}$ increased up to $89.9 \%$. From a hydrological context the equation may be plausible. A low DD commonly indicates that much rainfall in a catchment is discharged by (delayed) groundwater flow where the groundwater domain is recharged by the percolation of rain water. PERC also may relate to SAAR where higher SAAR values may result in higher percolation values. The statistical characteristics are shown in Table 5 .

CFLUX: in this study CFLUX has negative correlation with SHAPE $(-0.83)$ and positive correlation with PDRY (0.81). Therefore optimisation of the linear relation with the forward entry method is executed with SHAPE as the initial variable. The results of the stepwise forward entry regression showed that CFLUX is correlated with SHAPE, PDRY (mean precipitation dry season) and PET (mean annual evapotranspiration) with $R^{2}$ of $99.8 \%$. Since capillary transport is triggered by atmospheric forcing the correlation of CFLUX to PDRY and to PET may be plausible. The correlation to SHAPE is not plausible. The statistical characteristics are shown in Table 5.

Results of the regression analysis for establishing the regional model indicate that statistically most significant regression equations can be obtained despite the fact that MPs can have low correlation to the selected PCCs (see Table 4). Obviously for such relations it is difficult to reason for hydrologic plausibility. We note, however, that in litterateur (e.g. Deckers et al., 2010) more cases are known but also the use of PCCs with a high correlation not necessarily improve the regional model.

\subsection{Performance assessment of the regional model}

In most regionalisation studies, the validity of the regional model is assessed by its application to gauged catchments that are not used for establishing the regional model (see Sect. 5.7). Since in this work only a small number of gauged catchments is available, we used the regional model in Table 5 to estimate the model parameters for the gauged catchments using their PCCs. Simulated stream flow from the gauged catchments is compared to observed time series and assessments are by use of NS and RVE for the period 20012003. Table 6 shows NS and RVE values and the parameter values as derived from the regional model. NS values range between 0.54 and 0.85 whereas RVE values range between -42 and $13.3 \%$. For most catchments NS values are slightly lower than the results by MCS. RVE values for three catchments (i.e., Gumara, Megech, and Kelti) are much larger whereas for the remaining three catchments RVE have similar value. In general validation results suggest fair to good performance of the regional model. We note, however, that NS and RVE values that indicate the validity of the regional model potentially indicate better performance as compared when independent catchments are used. 
Table 6. Assessment of the regional model for gauged catchments (2001-2003).

\begin{tabular}{lcccccccccr}
\hline & FC & BETA & LP & ALFA & $K_{\mathrm{q}}$ & $K_{\mathrm{S}}$ & PERC & CFLUX & NS $(-)$ & RVE (\%) \\
\hline Ribb & 298 & 1.17 & 0.71 & 0.29 & 0.055 & 0.098 & 1.10 & 0.62 & 0.85 & -1.3 \\
Gilgel Abay & 333 & 1.99 & 0.72 & 0.25 & 0.086 & 0.084 & 1.13 & 1.10 & 0.83 & 0.1 \\
Gumara & 307 & 1.48 & 0.83 & 0.28 & 0.057 & 0.079 & 1.40 & 0.71 & 0.75 & -22.8 \\
Megech & 201 & 1.54 & 0.70 & 0.29 & 0.031 & 0.085 & 1.52 & 0.79 & 0.54 & 13.3 \\
Koga & 659 & 1.32 & 0.41 & 0.43 & 0.068 & 0.061 & 1.63 & 0.75 & 0.65 & -1.1 \\
Kelti & 437 & 2.45 & 0.72 & 0.39 & 0.072 & 0.054 & 1.18 & 1.06 & 0.53 & -42.0 \\
\hline
\end{tabular}

\subsection{Lake level simulations}

For lake level simulation all mass balance terms in Eq. (16) are solved on a daily time step and results of lake level simulations are compared to observed lake levels. As described in Sect. 5.3 for lake evaporation a procedure is applied that combines the Penman-combination equation and a satellite based approach where albedo is estimated on a daily base to make up an annual cycle. Albedo ranged from 0.08 to 0.16 by the gradually changing solar zenith angle during the course of the year. Averaged daily evaporation is estimated at $4.6 \mathrm{~mm} \mathrm{day}^{-1}$ for the period 1992-2003 with a long-term averaged annual evaporation of $1563 \mathrm{~mm} \mathrm{yr}^{-1}$. Minimum daily evapotranspiration is $2 \mathrm{~mm} \mathrm{day}^{-1}$ and maximum is $6 \mathrm{~mm} \mathrm{day}^{-1}$. Lake evaporation is lower than estimated in Wale et al. (2009) $\left(1690 \mathrm{~mm} \mathrm{yr}^{-1}\right)$ but higher than in Kebebe et al. (2006) (1478 $\left.\mathrm{mm} \mathrm{yr}^{1}\right)$. Daily rainfall over Lake Tana is estimated by spatial interpolation of gauge data from Bahir Dar, Chawhit, Zege, Deke Estifanos and Delgi station (Fig. 1). Inverse distance with power 2 resulted in an average lake precipitation of $1290 \mathrm{~mm} \mathrm{yr}^{-1}$.

The results of lake level simulation are shown in Fig. 6 where simulated levels are compared to observed lake levels. The results indicate a good match where climatic seasonality with clear dry and wet periods is well presented. Largest deviations are observed specifically during the first few and last few years of the simulation period. Obvious reasons that cause the deviations are difficult to identify and can relate to any of the water balance terms. A quantitative assessment indicates that the balance closure term is as large as $85 \mathrm{~mm} \mathrm{yr}^{-1}$ of the total lake inflow that comprised rainfall on the lake, and stream flow from gauged and ungauged catchments. This error accounts for $2.7 \%$ of the total lake inflow. In Wale et al. (2009) the closure error was $-170 \mathrm{~mm}$ and accounted for $5 \%$ of the total lake inflow. In this work the smaller inflow error did not result in better lake level simulation results when compared to Wale et al. (2009). Results of the lake level simulation are assessed by NS and RVE as well and resulted in values of 0.91 and $-2.17 \%$, respectively, whereas in Wale et al. (2009) NS was 0.90 and RVE was $1.6 \%$.
Table 7. Lake Tana water balance components simulated for the period 1994-2003.

\begin{tabular}{lrr}
\hline Water balance components & $\mathrm{mm} \mathrm{yr}^{-1}$ & $\mathrm{MCM} \mathrm{yr}^{-1}$ \\
\hline Lake areal rainfall & +1347 & +4104 \\
Gauged river inflow & +1254 & +3821 \\
Ungauged river inflow & +527 & +1605 \\
Lake evaporation & -1563 & -4762 \\
River outflow & -1480 & -4508 \\
Closure term & +85 & +260 \\
\hline
\end{tabular}

Compared to the work in Wale et al. (2009) differences in the annual lake balance are shown in Table 7. We note that refined procedures are applied in this work. For instance multi-objective model calibration by use of MCS is applied in this work, the procedure to estimate lake evaporation relies on daily varying albedo estimates and different PCCs are tested for regionalisation.

We note that there are still many sources of uncertainty and errors in the water balance but quantifying and reducing the errors is far from trivial. For instance, we assumed that lake-groundwater interaction is negligible; that for open water evaporation spatially averaged values can be used as estimated by the Penman-combination equation; that lake rainfall is sufficiently accurate represented by use of spatial interpolation methods that rely on rain gauge data observed on the land. Also we assume that the regional model is reliable and robust although we note that only six catchments were used for establishing the regional model. This number is small when compared to regionalisation studies in literature but indicates the true problem of data scarcity as common in less developed countries. Probably the only way to assess how uncertainty and errors effect results in this work is to find better approaches to describe and to represent the individual processes or to apply more advanced model calibration procedures where diagnostic information serves to improve modeling results (see Gupta et al, 2008; de Vos et al., 2011). Both, however, presumably requires that better and (much) more real world data in time and space dimensions becomes available. 

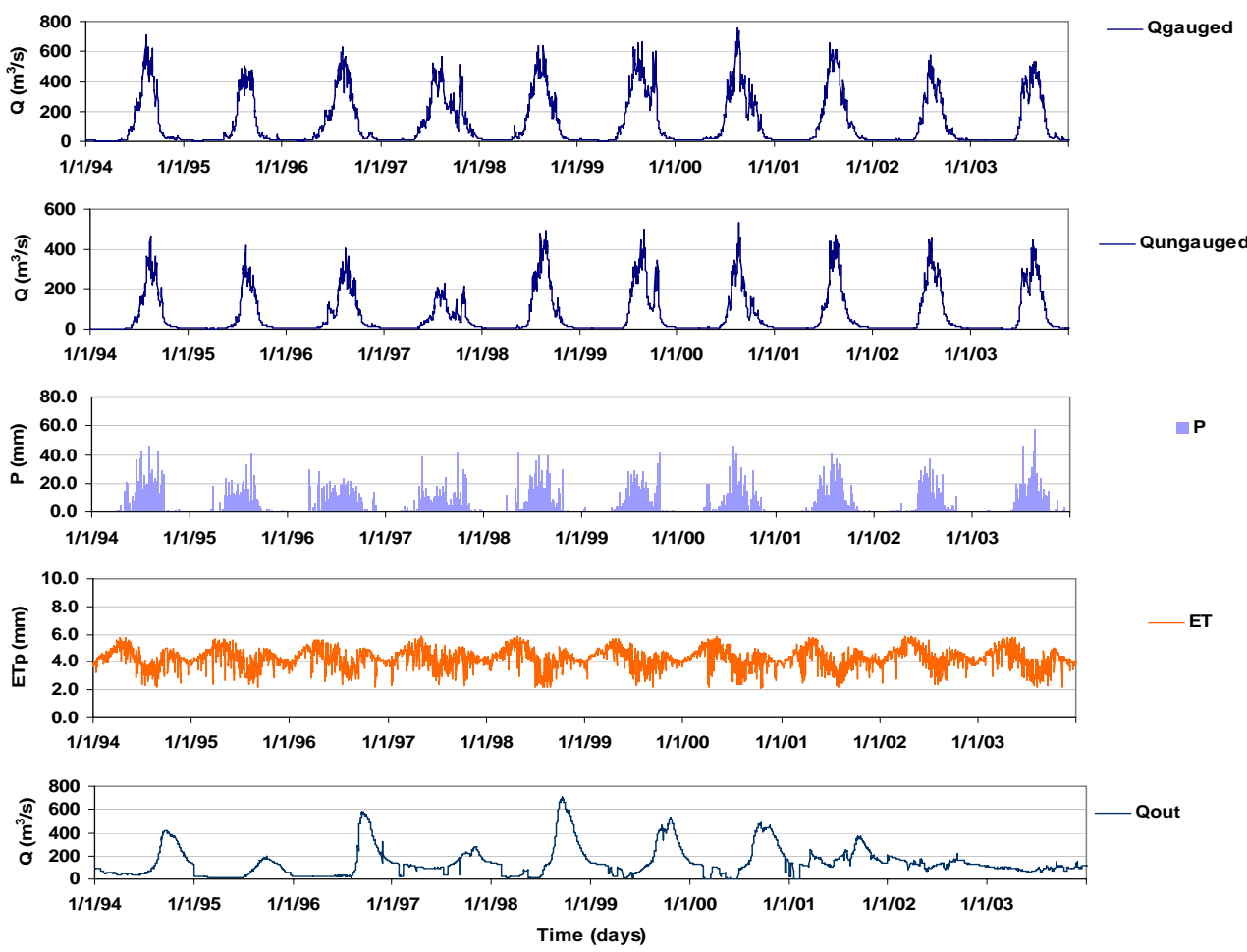

Fig. 6. Daily estimates of water balance terms of Lake Tana.

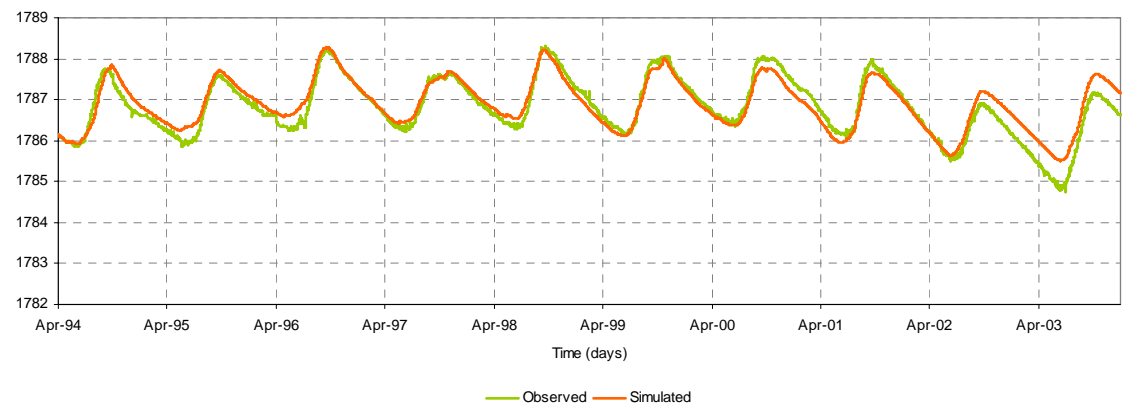

Fig. 7. Comparison of simulated to observed lake levels.

\section{Conclusions}

By availability of bathymetric relations, lake levels are simulated on daily base over the simulation period. All water balance terms of Lake Tana are estimated explicitly and results of lake level simulation showed NS of 0.91 and RVE of $-2.17 \%$. Results of this study show that the Lake Tana water balance can be closed with a closure error of $85 \mathrm{~mm} \mathrm{yr}^{-1}$ that accounts for $2.7 \%$ of the total lake inflow. Compared to previous studies on Lake Tana's water balance by Setgen et al. (2005); SMEC (2008); Kebede et al. (2006); Chebud and Melesse (2009) and Wale et al. (2009) results of this study indicate smallest closure error. In this work probably the most complete hydro-meteorological data set that is available for the basin is used. Runoff from gauged catchments is simulated by use of a simple conceptual rainfall-runoff model and a Monte Carlo procedure. Model parameters for the ungauged catchments are estimated by use of a regionalization procedure.

Regionalisation in this study is based on similarity principles of catchment characteristics and indicated that some $29.5 \%$ of inflow of Lake Tana is from ungauged systems while the area ungauged covers nearly $62 \%$. The estimated stream flow is lower than the results in Wale et al. (2009) and presumably is due to a number of reasons that relate to the use of the advanced model calibration procedure and 
the selection of a different set of physical catchment characteristics as used for regionalisation. Multi-objective model calibration by use of MCS indicated that a very large number of simulation runs must be executed. In this study a total of 900000 runs (i.e., $15 \times 60000$ runs) is executed and resulted in relatively high parameter variability when single best parameter sets are defined for each of the 15 MCS runs but indicated moderate variability when averaged parameter values are compared for the 25 best performing parameter sets. Optimized parameter values in this study differ from Uhlenbrook et al. (2010) who used 1000000 runs for the Gilgel Abay catchment. Reasons for the difference could be that, instead of selecting the single best performing parameter set, we averaged the parameter values over 15 MCS runs were values over each run already represent averages over the 25 best performing sets. Also the selected prior parameter ranges differ and a slightly different model structure is used. We note that manually calibrated parameter values in Wale et al. (2009) and Abdo et al. (2009) again differ.

Results of the regression analysis for establishing the regional model indicate that for all MPs statistically significant regression equations can be obtained. Relations, however, are not always plausible from a hydrological point of view. In this work it is shown that adding PCCs with high correlation to a regression relation not always results in an improved regional model. Out of the group of 22 PCCs only some 9 PCCs are used. PCCs most frequently used relate to topographic, morphologic and climatic catchment settings.

Critical to the results of the regionalisation procedure in this work is the low number of gauged catchments. By the relatively small size of the Lake Tana basin only nine gauged catchments were available from which only six catchments had stream flow time series that could be used. We note that in most regionalisation studies a much larger set of gauged catchments is available (see Merz and Blösch, 2004; Deckers at al., 2010; Young, 2006). Whether, however, the small set negatively affected our results is not entire clear. Validation results of the regional model in general do not suggest that the model should be rejected but also a normalization procedure of PCCs for both gauged and ungauged catchments indicates that inter catchment variability does not constrain regionalization.

The use of remote sensing approach for estimating lake water albedo proved that albedo values over Lake Tana changed over the year by changing solar zenith angles. The use of satellite based albedo estimates resulted in lake evaporation of $1563 \mathrm{~mm} \mathrm{yr}^{-1}$. This value is lower than estimated in Wale et al. (2009) $\left(1690 \mathrm{~mm} \mathrm{yr}^{-1}\right)$ but higher than in Kebebe et al. (2006) $\left(1478 \mathrm{~mm} \mathrm{yr}^{-1}\right)$. Further assessments on the estimation of Lake Tana evaporation is required to better assess accuracy of the lake water balance. Such however is topic of ongoing research and a field campaign has been executed in 2009 with the aim to estimate lake evaporation by an energy balance method. For further assessments on the accuracy of the water balance of Lake Tana we recommend that extensive uncertainty analysis are performed for all balance terms. In this work we ignored such analysis and is left for future work. A simple analysis is already shown in Wale et al. (2009).

Acknowledgements. The three anonymous reviewers are gratefully acknowledged for their valuable comments on our manuscript. We also acknowledge the Ethiopian Meteorological Agency and the Ethiopian Ministry of Water Resources for their support by supplying the time series data for rainfall and stream flow. This study was financially supported by the Netherlands Fellowship Programme (NFP).

Edited by: T. Steenhuis

\section{References}

Abdo, K. S., Fiseha, B. M., Rientjes, T. H. M., Gieske, A. S. M., and Haile, A. T.: Assessment of climate change impacts on the hydrology of Gilgel Abbay catchment in Lake Tana basin, Ethiopia, Hydrol. Process., 23(26), 3661-3669, 2009.

Bastola, S., Ishidaira, H., and Takeuchi, K.: Regionalisation of hydrological model parameters under parameter uncertainty: A case study involving TOPMODEL and basins across the globe, J. Hydrol., 357(3-4), 188-206, 2008.

Beven, K. and Binley, A.: The future of distributed models: model calibration and uncertainty prediction, Hydrol Process., 6, 279298, 1992.

Blöschl, G. and Sivapalan, M.: Scale issues in hydrological modelling: a review, Hydrol Process., 9, 251-290, 1995.

Booij, M. J.: Impact of climate change on river flooding assessed with different spatial model resolutions, J. Hydrol., 303, 176198, 2005.

Chebud, Y. A. and Melesse, A. M.: Modelling lake stage and water balance of Lake Tana, Ethiopia, Hydrol. Process., 23, 35343544, 2009.

Conway, D.: A water balance model of the Upper Blue Nile in Ethiopia, Hydrological Sciences Journal-Journal Des Sciences Hydrologiques, 42(2), 265-286, 1997.

Deckers, D. L. E. H., Booij, M. J., Rientjes, T. H. M., and Krol, M. S.: Catchment variability and parameter estimation in multiobjective regionalisation of a rainfall-runoff model, Water Resour. Manage., 24, 3961-3985, doi:10.1007/s11269-010-9642-8, 2010.

de Vos, N. J. and Rientjes, T. H. M.: Multi-objective performance comparison of an artificial neural network and a conceptual rainfall-runoff model, Hydrol. Sci. J., 52(1), 397-413, 2007.

de Vos, N. J. and Rientjes, T. H. M.: Multi-objective training of artificial neural networks for rainfall-runoff modeling, Wat. Resour. Res., 44, W08434, doi:10.1029/2007WR006734, 2008.

de Vos, N. J., Rientjes, T. H. M., and Gupta, H. V.: Diagnostic evaluation of conceptual rainfall-runoff models using temporal clustering, Hydrol. Process., 24, 2840-2850, doi:10.1002/hyp.7698, 2010.

Diermanse, F. L. M.: Physically based modelling of rainfall-runoff processes. PhD thesis, Delft University Press, Delft, 2001.

Gupta, H. V., Wagener, T. Y., and Liu, Y.: Reconciling theory with observations: Elements of a diagnostic approach to model evaluation, Hydrol. Process., 22, 3802-3813, 2008. 
Haberlandt, U., Klöcking, B., Krysanova, V., and Becker, A.: Regionalisation of the base flow index from dynamically simulated flow components - a case study in the Elbe River Basin, J. Hydrol., 248, 35-53, 2001.

Haile, A. T., Rientjes, T. H. M., Gieske, M., and Gebremichael, M.: Rainfall Variability over mountainous and adjacent lake areas: the case of Lake Tana basin at the source of the Blue Nile River, J. Appl. Meteor. Climatol., 48, 1696-1717, 2009.

Haile, A. T., Rientjes, T. H. M, Gieske, A., and Gebremichael, M.: Rainfall estimation at the source of the Blue Nile: A multispectral remote sensing approach, Int. J. Appl. Earth Obs. Geoinf., JAG, 12, Supplement 1, S76-S82, 2010.

Haile, A. T., Rientjes, T. H. M., Gieske, A., Jetten, V., and Mekonnen, G.: Satellite remote sensing and conceptual cloud modeling for convective rainfall simulation, Adv. Water Res., 34, 26-37, doi:10.1016/j.advwatres.2010.08.007, 2011a.

Haile, A. T., Rientjes, T. H. M., Habib, E., Jetten, V., and Gebremichael, M.: Rain event properties at the source of the Blue Nile River, Hydrol. Earth Syst. Sci., 15, 1023-1034, doi:10.5194/hess-15-1023-2011, 2011 b.

Harlin, J. and Kung, C.: Parameter uncertainty and simulation of design floods in Sweden, J. Hydrol., 137, 209-230, 1992.

Heuvelmans, G., Muys, B., and Feyen, J.: Regionalisation of the parameters of a hydrological model: Comparison of linear regression models with artificial neural nets, J. Hydrol., 319(1-4), 245-265, 2006.

Hundecha, Y. and Bárdossy, A.: Modeling of the effect of land use changes on the runoff generation of a river basin through parameter regionalization of a watershed model, J. Hydrol., 292(1-4), 281-295, 2004.

Kebede, S., Travi, Y., Alemayehu, T., and Marc, V.: Water balance of Lake Tana and its sensitivity to fluctuations in rainfall, Blue Nile basin, Ethiopia, J. Hydrol., 316(1-4), 233-247, 2006.

Kim, U., Kaluarachchi, J. J., and Smakhtin, U.: Generation of monthly precipitation under climate change for the Upper Blue Nile river basin Ethiopia, J. Am. Water Resour. As., 44(2), 1-17, doi:10.1111/j.1752-1688.2008.00220.x., 2008.

Klemeš, V.: Operational testing of hydrological simulation models, Hydrol. Sci. J., 31, 13-24, 1986.

Liang, S.: Narrowband to broadband conversions of land surface albedo: I. Formulae, Remote Sens. Environ., 76, 213-238, 2001.

Liang, S., Shuey, C., Russ, A., Fang, H., Walthall, C., and Daughtry, C.: Narrowband to broadband conversions of land surface albedo: II. Validation, Remote Sens. Environ., 84, 25-41, 2002.

Lidén, R. and Harlin, J.: Analysis of conceptual rainfall-runoff modelling performance in different climates, J. Hydrol., 238, 231-247, 2000.

Lindström, G., Johansson, B., Persson, M., Gardelin, M., and Bergström, S.: Development and test of the distributed HBV-96 hydrological model, J. Hydrol., 201, 272-288, 1997.
Merz, R. and Blöschl, G.: Regionalisation of catchment model parameters, J. Hydrol., 287, 95-123, 2004.

Nash, J. E. and Sutcliffe, J. V.: River flow forecasting through conceptual models, Part I. A discussion of principles, J. Hydrol., 10, 282-290, 1970.

Rientjes, T. H. M., Haile, A. T., Mannaerts, C. M. M., Kebede, E., and Habib, E.: Changes in land cover and stream flows in Gilgel Abbay catchment, Upper Blue Nile basin - Ethiopia, Hydrol. Earth Syst. Sci. Discuss., 7, 9567-9598, doi:10.5194/hessd7-9567-2010, 2010.

Schaefli, B. and Gupta, H. V.: Do Nash values have value?, Hydrol. Process., 21, 2075-2080, doi:10.1002/hyp.6825, 2007.

Sefton, C. E. M. and Howarth, S. M.: Relationships between dynamic response characteristics and physical descriptors of catchments in England and Wales, J. Hydrol., 211, 1-16, 1998.

Seibert, J.: Estimation of parameter uncertainty in the HBV model, Nordic Hydrol., 28, 4-5, 1997.

Seibert, J.: Regionalisation of parameters for a conceptual rainfallrunoff model, Agr. Forest Meteorol., 98-99, 279-293, 1999.

Setegn, S. G., Srinivasan, R., and Dargahi, B., Hydrological Modelling in the Lake Tana Basin, Ethiopia Using SWAT Model, The Open Hydrology Journal, 2, 49-62, 2008.

Sivapalan, M., Takeuchi, K., Franks, S. W., Gupta, V. K., Karambiri, H., Lakshmi, V., Liang, X., McDonnell, J. J., Mendiondo, E. M., O'Connell, P. E., Oki, T., Pomeroy, J. W., Schertzer, D., Uhlenbrook, S., and Zehe, E.: IAHS Decade on Predictions in Ungauged Basins (PUB), 2003-2012: Shaping an exciting future for the hydrological sciences, Hydrol. Sci. J., 48, 857-880, 2003.

SMEC: Hydrological Study of the Tana-Beles sub-basins, main report, Snowy Mountains Engineering Corporation, Australia, 2008.

SMHI: Integrated Hydrologic Modelling System (IHMS), Manual version 5.1., 2006.

Uhlenbrook, S., Mohamed, Y., and Gragne, A. S.: Analyzing catchment behavior through catchment modeling in the Gilgel Abay, Upper Blue Nile River Basin, Ethiopia, Hydrol. Earth Syst. Sci. 14, 2153-2165, doi:10.5194/hess-14-2153-2010, 2010.

Wagener, T. and Wheater, H. S.: Parameter estimation and regionalization for continuous rainfall-runoff models including uncertainty, J. Hydrol., 320, 132-154, 2006.

Wale, A., Rientjes, T. H. M., Gieske, A. S. M., and Getachew, H. A.: Ungauged catchment contributions to Lake Tana's water balance, Hydrol. Process., 23(26), 3682-3693, 2009.

$\mathrm{Xu}, \mathrm{C} .:$ Testing the transferability of regression equations derived from small sub-catchments to a large area in central Sweden, Hydrol. Earth Syst. Sci., 7, 317-324, doi:10.5194/hess-7-317-2003, 2003.

Young, A. R.: Stream flow simulation within UK ungauged catchments using a daily rainfall-runoff model, J. Hydrol., 320(1-2), 155-172, 2006. 